\title{
Biodiversity schemes take root in China
}

\section{David Cyranoski}

For years, environmentalists have watched aghast as huge farming and construction projects have threatened to wipe out swaths of China's ecology. But as modernization marches westwards across the country, scientists are proposing initiatives to help conserve a region of exceptional biodiversity.

On 24 October, researchers from the Chinese Academy of Sciences (CAS) Institute of Botany in Kunming met with government officials to negotiate funding for a national germplasm bank to be based at the institute. They are now optimistic that they will obtain 148 million renminbi (US\$18 million) for the bank, plans for which passed a government-sponsored scientific evaluation in early September.

And on 27 October, the CAS Kunming Institute of Zoology hosted a conference to launch a collaboration between the CAS, Germany's Max Planck Society and the University of Chicago to train China's next generation of conservation biologists.

The two initiatives add momentum to the expansion of China's nature reserves, which have doubled in number in the past five years and now occupy $16 \%$ of its land area, says Zhigang Jiang, a zoologist at the CAS Institute of Zoology in Beijing and director of China's Endangered Species Scientific Commission. The reserves are concentrated in western and southwestern regions of the country.

The latest schemes will seek to protect some of the world's most ecologically diverse regions, says botanist DeZhu Li, deputy

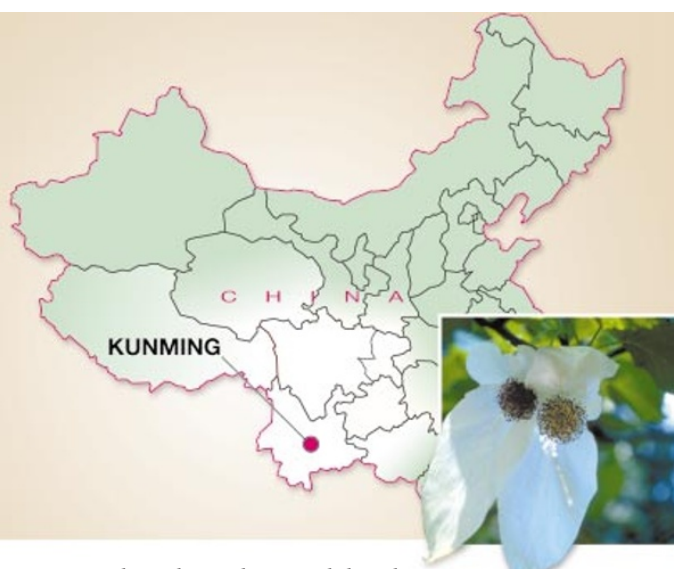

Species such as the endangered davidia tree

(inset) face severe ecological pressures in southwestern China.

director of the Kunming botanical institute.

Ecologists have long been concerned for southwestern China's endangered species such as the davidia tree and Yunnan snubnose monkey - arguing that they are under threat from agricultural and industrial development in the region. Five years ago, Zhengyi Wu, a former director of the botanical institute, brought the matter directly to the attention of then Chinese prime minister Zhu Rongji. "Scientists called on Zhu to take steps before industrialization destroyed the environment," says Li. "We told him that before any major industrial change, protection of the environment is urgent."

Zhu's support, before his retirement last March, led to this month's negotiations on the germplasm bank, which would store seeds from thousands of plants and samples from microorganisms native to the southwestern regions of Yunnan, Guizhou, Sichuan, Guanxi and Tibet. The bank will also support in vitro fertilization and cryogenic preservation of plants.

The project is being watched closely by ecologists outside China. Hugh Pritchard, head of seed conservation at Britain's Millennium Seed Bank Project based at the Royal Botanic Gardens in Kew, says: "This is the only other serious attempt at mass conservation of plant biodiversity that I know of."

Li says that the Chinese group plans to collect 4,000 seeds over the next five years, eventually rising to 19,000 . Pritchard adds that many samples will also be deposited with the British project, helping it towards its goal of collecting 24,000 species by 2010. The Chinese effort will be a useful ally to his team's project, Pritchard says.

But a lack of trained professionals might hamper China's conservation ideals. "Much of this biodiversity has never been handled before," says Pritchard. He says that the project will throw up some interesting problems, such as how to differentiate between seeds that are no longer viable and those that are just taking a long time to germinate.

Chung-I Wu, an evolutionary geneticist at the University of Chicago who helped to organize the 27 October meeting, says that China needs a new generation of biologists to implement its conservation plans. "For conservation biology to have a future, it must have a sound scientific basis," he argues. "It will need to attract those who might otherwise become the brightest computer scientists."

\section{Europe kills cash flow to EURESCO science meetings}

\section{Quirin Schiermeier, Munich}

A popular series of intimate, cutting-edge scientific meetings for European researchers is facing the axe because it doesn't fit the priorities of the European Union (EU) Framework programme of research.

The European Research Conferences (EURESCO) were started in 1990 as Europe's answer to the Gordon Research Conferences, which attract top researchers from all over the world to discuss specific scientific topics, but usually take place in the United States.

The EU's Sixth Framework Programme, which has allocated $e \mathbf{4 0}$ million (US\$47 million) over four years for conferences and training courses, gives priority to helping young researchers attend large meetings or small events with a strong element of training, such as summer schools. As a result, all of this year's applications for grants to support
EURESCO meetings have been turned down. Some 40,000 scientists have attended more than 490 EURESCO meetings, which are organized by the Strasbourg-based European Science Foundation (ESF). Most pay to attend, but extra money is needed for travel and accommodation for speakers. Gordon conferences get this money from corporate sponsorship, but the EURESCO meetings have relied on EU grants.

Now competition for such grants is intense, says Nicholas Deliyanakis, a project officer at the European Commission's research directorate. Only $10 \%$ of all proposed events have been selected for funding under the Sixth Framework Programme. Deliyanakis says that although EURESCO meetings are not explicitly excluded, they are unlikely to be supported.

"EURESCO meetings were always absolute highlights — short, intensive and immensely productive," says Thomas Stocker, a climate researcher at the University of Bern in Switzerland.

"I would be very sad if EURESCO meetings were to be abandoned," agrees Stig Stenholm, a quantum physicist at the Royal Institute of Technology in Stockholm, Sweden. "In my field, they have substantially helped to forge a strong European research community."

Seventeen EURESCO meetings will still be held next year, with a further six in 2005 , on the basis of grants already approved under the previous Framework programme. After that, the ESF is exploring options for continuing the series. "We are very keen for these conferences to be re-established," says Enric Banda, the ESF's secretary general. www.esf.org/esf_euresco_home.php?language=0 